\title{
Explosion prevention and mitigation in plants which process, generate and store combustible dusts
}

\author{
Adrian Marius Jurca ${ }^{1 *}$, Mihaela Părăian ${ }^{1}$, and Niculina Vătavu $^{1}$ \\ ${ }^{1}$ National Institute for Research and Development in Mine Safety and Protection to Explosion - \\ INSEMEX, 32-34 G-ral Vasile Milea street, 332047, Petroșani, Hunedoara county, România
}

\begin{abstract}
Combustible dusts which are present in workplaces are a significant hazard which cannot be ignored by the plant owners, managers and workers. Combustible dust deflagrations and explosions have caused large numbers of deaths and catastrophic property damages in various industries, ranging from pharmaceutical plants to sugar factories. One may say that dust explosions in process industries always start inside process equipment such as mills, dryers, filters. Such events may occur in any process in which a combustible dust is handled, produced or stored, and can be triggered by any energy source, including static electricity, friction and hot surfaces.

For any combustible dust type, several important parameters have to be taken into account when designing and using protective systems: i.e. the ease with which dust clouds ignite and their burning rates, maximum explosion pressure, maximum rate of explosion pressure rise. These parameters vary considerably depending on the dust type, their knowledge being a first step for carrying out a proper explosion risk assessment in installations which circulate combustible dusts.

The paper presents the main aspects concerning explosion protection which have to be taken into account when designing protective systems intended to be used in explosive atmospheres generated by combustible dusts and the importance of selecting the proper explosion protection technique.
\end{abstract}

\section{Introduction}

Industrial explosions are known to be a significant hazard during the processing, storage and transportation of flammable materials. Combustible dust explosions have accounted for a large number of deaths, disappearance of companies, and high financial losses, and yet they are one of the least recognized industrial hazards. Such explosions can occur within any process which handles, produces or stores a combustible dust, and it can be triggered by any energy source, including static electricity, friction and hot surfaces.

Explosion prevention and protection concept comprises a series of measures to be applied within installations which circulate flammable substances. The first measure is to avoid or

\footnotetext{
*Corresponding author: adrian.jurca@insemex.ro
} 
to reduce the explosive atmosphere generated, the second one is to avoid possible ignition sources and the last one is the measure for stopping explosions in the initial phases and/or for limiting the effects of these events by using protective systems.

For this reason, proper precautions have to be adopted, so that to ensure that all equipment is protected and the possibility for igniting the explosive atmosphere is diminished. [1]

Explosion prevention and protection measures are intended for eliminating or avoiding the conditions which may lead to explosions.

The purpose of explosion preventing and protection measures is to prevent explosion occurrence, by eliminating or avoiding the conditions leading to explosions. For any combustible dust type, several important parameters have to be taken into account when designing and using protective systems: i.e., the ease with which dust clouds ignite and their burning rates, maximum explosion pressure, maximum rate of explosion pressure rise. These parameters vary considerably depending on the dust type, their knowledge being a first step for carrying out a proper explosion risk assessment in installations which circulate combustible dusts. Once known, the protection/prevention measures can be correlated with the safety characteristics.

Explosion protection and prevention involve the fulfillment of mandatory requirements for the safe handling and processing of solid materials, with fine particle dimensions, among which are mentioned: knowledge of characteristics which influence safety, knowledge of measures for controlling and monitoring dust releases in technological processes, of designing installations for handling dusts, respectively solid knowledge with regard to the implementation of a proper cleaning schedule in workplaces.

In many cases, the accumulation of explosive atmospheres and the ignition sources are not possible to be avoided. In this situation, an explosion might occur if the combustible dust is present in suspension, mixed with air (with enough oxygen), within the explosion limits, together with an ignition source of enough energy - Figure 1. [1]

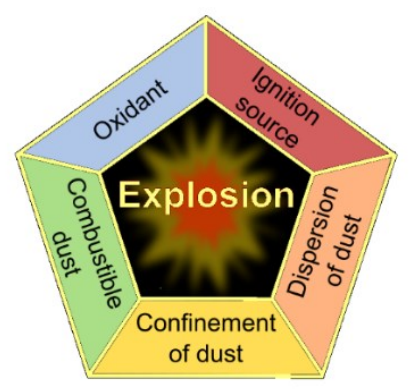

Fig. 1. Explosion pentagon

Table 1 gives an overview of the most important methods which are currently used for preventing and mitigating dust explosions in process industries. The industry will always need proper tools and measures which can be implemented more or less immediately.

Table 1. Schematic overview of means of preventing and mitigating dust explosions.

\begin{tabular}{|c|c|c|}
\hline \multicolumn{2}{|c|}{ Explosion prevention } & Explosion mitigation \\
\hline $\begin{array}{c}\text { Preventing explosive dust } \\
\text { clouds }\end{array}$ & Preventing ignition sources & \\
\hline $\begin{array}{c}\text { Inerting of dust clouds by } \\
\mathrm{N}_{2}, \mathrm{CO}_{2} \text { and rare gases }\end{array}$ & $\begin{array}{c}\text { Smouldering combustion } \\
\text { in dust, dust fires }\end{array}$ & $\begin{array}{c}\text { Explosion isolation } \\
\text { (pressure } \\
\text { resistant construction) }\end{array}$ \\
\hline Inerting of dust cloud by & Other types of open flames & Explosion venting \\
\hline
\end{tabular}




\begin{tabular}{|c|c|c|}
\hline \multicolumn{2}{|c|}{ Explosion prevention } & \multirow[t]{2}{*}{ Explosion mitigation } \\
\hline $\begin{array}{l}\text { Preventing explosive dust } \\
\text { clouds }\end{array}$ & Preventing ignition sources & \\
\hline adding inert dust & (e.g., hot work) & \\
\hline $\begin{array}{l}\text { Keeping dust concentration } \\
\text { outside explosive range }\end{array}$ & $\begin{array}{l}\text { Hot surfaces (electrically or } \\
\text { mechanically heated) }\end{array}$ & $\begin{array}{c}\text { Flameless explosion } \\
\text { venting }\end{array}$ \\
\hline \multirow[t]{3}{*}{$\begin{array}{c}\text { Inherently safer process } \\
\text { design }\end{array}$} & $\begin{array}{l}\text { Heat from mechanical } \\
\text { impact (metal sparks and } \\
\text { hot-spots) }\end{array}$ & $\begin{array}{c}\text { Explosion } \\
\text { suppression }\end{array}$ \\
\hline & $\begin{array}{c}\text { Electric sparks and arcs and } \\
\text { electrostatic discharges }\end{array}$ & $\begin{array}{l}\text { Partial inerting of dust } \\
\text { cloud by inert gas }\end{array}$ \\
\hline & & $\begin{array}{l}\text { Good housekeeping (dust } \\
\text { removal/cleaning) }\end{array}$ \\
\hline
\end{tabular}

Basic knowledge concerning flame propagating in dust clouds and explosion characteristics is the key for the proper design of mitigation measures, such as systems for dust explosion venting, suppression and isolation. The paper presents the main aspects concerning explosion protection which have to be taken into account when designing protective systems intended to be used in explosive atmospheres generated by combustible dusts and the importance of selecting the proper explosion protection technique.

\section{Importance of explosion characteristics in the design and selection of protective systems}

Explosion hazard is defined as the most representative explosive detrimental event that may occur due to an ignition in a technological installation. The first step in order to determine the worst case explosion has to be the determination of explosion's fuel characteristics, in compliance with the accepted test procedures, as provided in the specialized technical literature, SR EN 14034-1+A1:2011-Determination of explosion characteristics of dust clouds - Part 1: Determination of the maximum explosion pressure $\mathrm{p}_{\max }$ of dust clouds, $\mathrm{SR}$ EN 14034-2+A1:2011-Determination of explosion characteristics of dust clouds - Part 2: Determination of the maximum rate of explosion pressure rise $(\mathrm{dp} / \mathrm{dt})_{\max }$ of dust clouds $[2,3]$.

The testing methodology establishes the representative conditions for the fuel concentration, homogeneity and turbulence, expressed through the two main explosion parameters $p_{\max }$ and $\mathrm{K}_{\max }$. These two parameters are the basis for explosion venting, suppression and isolation requirements assessment.

For example, the minimum efficiency criterion for an explosion suppression system is for the suppressed explosion overpressure to have a lower value than the known pressure resistance of the weakest component in the equipment. In such situations, measures have to be taken for limiting the explosion down to an acceptable extent. Such measures are: pressure resistant design, pressure release, explosion suppression, flame and explosion propagation prevention $[4,5,6,7]$.

Explosion suppression represents the technique in which the combustion of an explosive atmosphere is detected and stopped when it is in the incipient phase, when the explosive atmosphere combustion finds itself in closed or partially closed volumes, thus limiting the development of pressures that could cause failures. Suppression systems are designed in such a manner so that to react in the incipient phase of the explosion, and their counteraction must have an optimal effect, taking into account two of the most important explosion parameters of combustible substances $(\mathrm{dp} / \mathrm{dt})_{\max }$ - the maximum rate of explosion pressure rise $[\mathrm{bar} / \mathrm{s}]$ and $\mathrm{p}_{\max }-$ the maximum explosion pressure [bar].[7] 
Maximum explosion pressure - $\mathbf{p}_{\max }$ - the maximum pressure value occurring during an explosion of an air-dust mixture with optimal concentration, in a confined vessel, in specified testing conditions - Figure 2 .

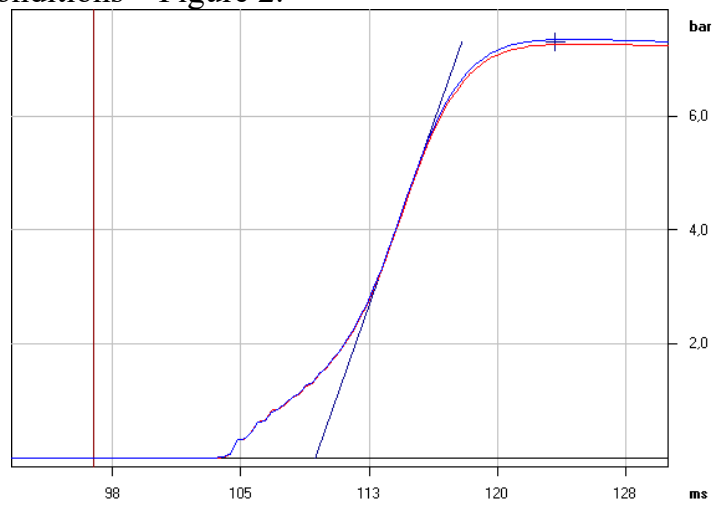

Fig. 2. Graphic representation of the maximum explosion pressure $-p_{\max }$

Maximum rate of explosion pressure rise - (dp/dt)max - the maximum value of pressure rise on the time unit in a confined vessel, during an explosion of an air-dust mixture with optimal concentration, in specified testing conditions - Figure 3 (see the cubic law - equation 1).

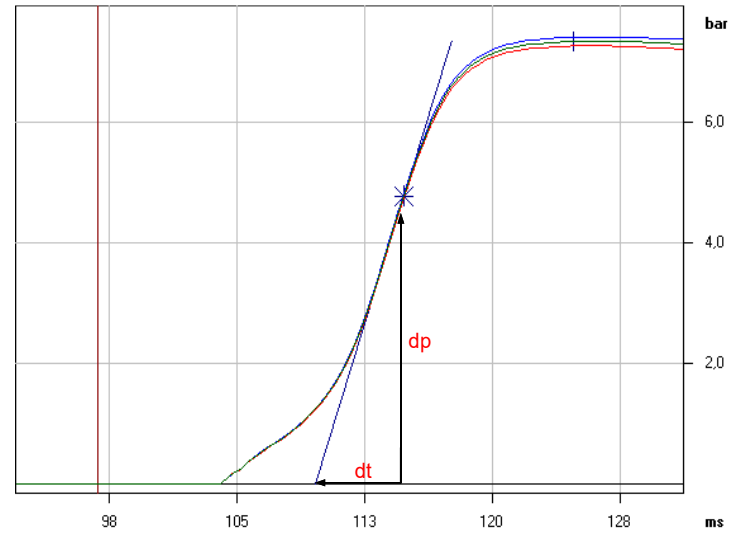

Fig. 3. Graphic representation of the maximum explosion pressure increase rate $-(\mathrm{dp} / \mathrm{dt})_{\max }$

The cubic law is given by the formula:

$$
(d p / d t)_{\max } \cdot V^{I / 3}=\text { const }=K_{S t},
$$

\section{where:}

- $\mathrm{K}_{\mathrm{St}}$ - parameter specific to dusts and tests, calculated according to the cubic law. Its value is numerically equal to the maximum explosion pressure rise in a $1 \mathrm{~m}^{3}$ vessel, in specified test conditions;

- V - vessel volume $\left[\mathrm{m}^{3}\right]$.

The combustible dusts are classified according to the $\mathrm{K}_{\mathrm{St}}$ value (explosion index for combustible dusts), as shown in table 2. 
Table 2. Explosion index for combustible dusts

\begin{tabular}{|c|c|c|}
\hline $\begin{array}{c}\text { Dust explosion } \\
\text { index }\end{array}$ & $\begin{array}{c}\mathbf{K} \mathbf{S t} \\
{\left[\mathbf{b a r} \cdot \mathbf{m} \cdot \mathbf{s}^{-\mathbf{1}}\right]}\end{array}$ & Characteristic \\
\hline St 0 & 0 & No explosion \\
\hline St 1 & $>0 \div 200$ & Weak explosion \\
\hline St 2 & $>200 \div 300$ & Strong explosion \\
\hline St 3 & $>300$ & Very strong explosion \\
\hline
\end{tabular}

\section{Device for determining explosion characteristics}

One of mostly used devices for determining the safety parameters for combustible dusts is the KSEP-20, consisting in a spherical explosion vessel, explosion-proof, manufactured from stainless steel with a volume of $20 \mathrm{dm}^{3}$, as shown in Figure 4. The heat absorbent is represented by a water curtain.

For performing the tests, the dust is dispersed in the sphere from the pressurized dust container, through a fast-acting valve and a dispersion nozzle. The fast-acting valve is pneumatically opened and closed, with the help of an auxiliary piston. The compressed air valves are activated electrically. The ignition source is placed in the center of the sphere.

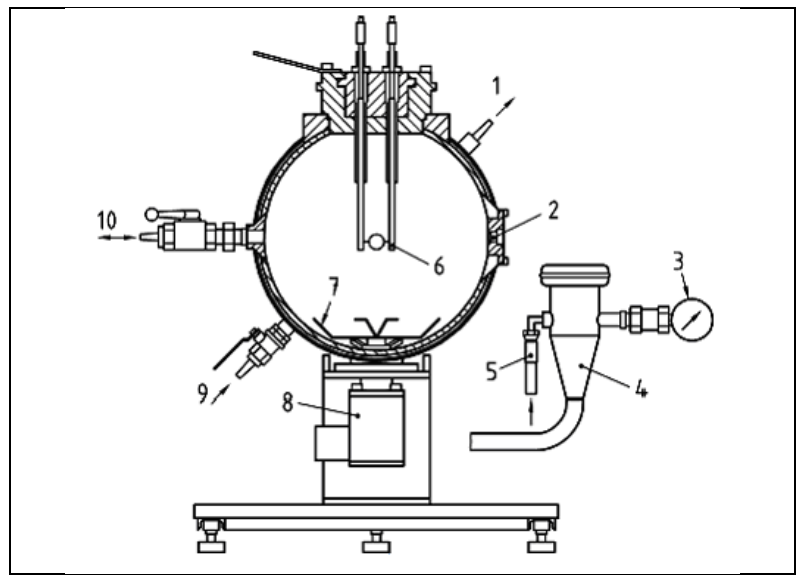

Legend:

1water outlet opening

2 pressure transducers

3 manometer

4 dust recipient $\left(0,6 \mathrm{dm}^{3}\right)$

5 air inlet opening
6 ignition source

7 dispersing nozzle

8 fast acting valve

9 water inlet opening

10 outlet opening (air, reaction products)

Fig. 4. Test installation type KSEP-20

According to the required parameter determined, the commands are sent to the testing installation using specialized software. Two piezoelectric pressure transducers are placed on the inner wall of the explosion vessel, in order to record pressure variations in the explosion generated inside the vessel. At the end of the test, based on the collected data are generated the diagrams required for assessing the explosion parameters [8].

The recorded and analysed explosion parameters are: maximum explosion pressure $\mathrm{p}_{\max }[\mathrm{bar}]$ and the maximum rate of explosion pressure rise - $(\mathrm{dp} / \mathrm{dt})_{\max }[\mathrm{bar} / \mathrm{s}]$. Table 3 presents a series of results for certain types of combustible dust. 
Table 3. Explosion characteristics for certain types of combustible dust

\begin{tabular}{|c|c|c|c|c|}
\hline Dust sample & $\begin{array}{c}\text { Dust } \\
\text { concentration } \\
{\left[\mathbf{g} / \mathbf{m}^{\mathbf{3}}\right]}\end{array}$ & $\begin{array}{c}\text { Maximum } \\
\text { explosion } \\
\text { pressure - } \mathbf{p m a x}_{\max } \\
{[\mathbf{b a r}]}\end{array}$ & $\begin{array}{c}\text { Maximum rate of } \\
\text { explosion pressure } \\
\text { rise - } \mathbf{( d p / d t )} \\
{[\mathbf{b a r} / \mathbf{s}]}\end{array}$ & $\begin{array}{c}\text { Explosion } \\
\text { index }-\mathbf{K} \text { st } \\
{[\mathbf{b a r} \cdot \mathbf{m} / \mathbf{s}]}\end{array}$ \\
\hline Grain & 750 & 6,7 & 487 & 132 \\
\hline Aluminium & 500 & 8,4 & 914 & 248 \\
\hline Novaminsulfon & 500 & 7,3 & 385 & 104 \\
\hline Solupred & 500 & 7,1 & 390 & 106 \\
\hline Niacin & 500 & 7,8 & 889 & 241 \\
\hline
\end{tabular}

Once the explosion characteristics for a combustible dust from an installation are known, proper protection systems can be designed and implemented so that to ensure a high safety level. In this regard, in the following is presented a simplified logical diagram for choosing explosion protection measures (protective systems), depending on the placement of the installations (inside or outside buildings), on the implementation of protective systems, on the maximum explosion pressure, and implicitly on the Kst explosion index.

\section{Selection of proper protective systems}

A simplified chart, provided below in Figure 5, proposes a step-by-step method to select the appropriate explosion protection technique - the protective systems. The initial stage is to determine whether the handled material is combustible or not. This can be achieved by testing. Then different questions guide the user to the appropriate protection solution between isolation, venting, flameless venting and suppression. At the end of the process, the user also needs to consider isolation if the enclosure has connections.

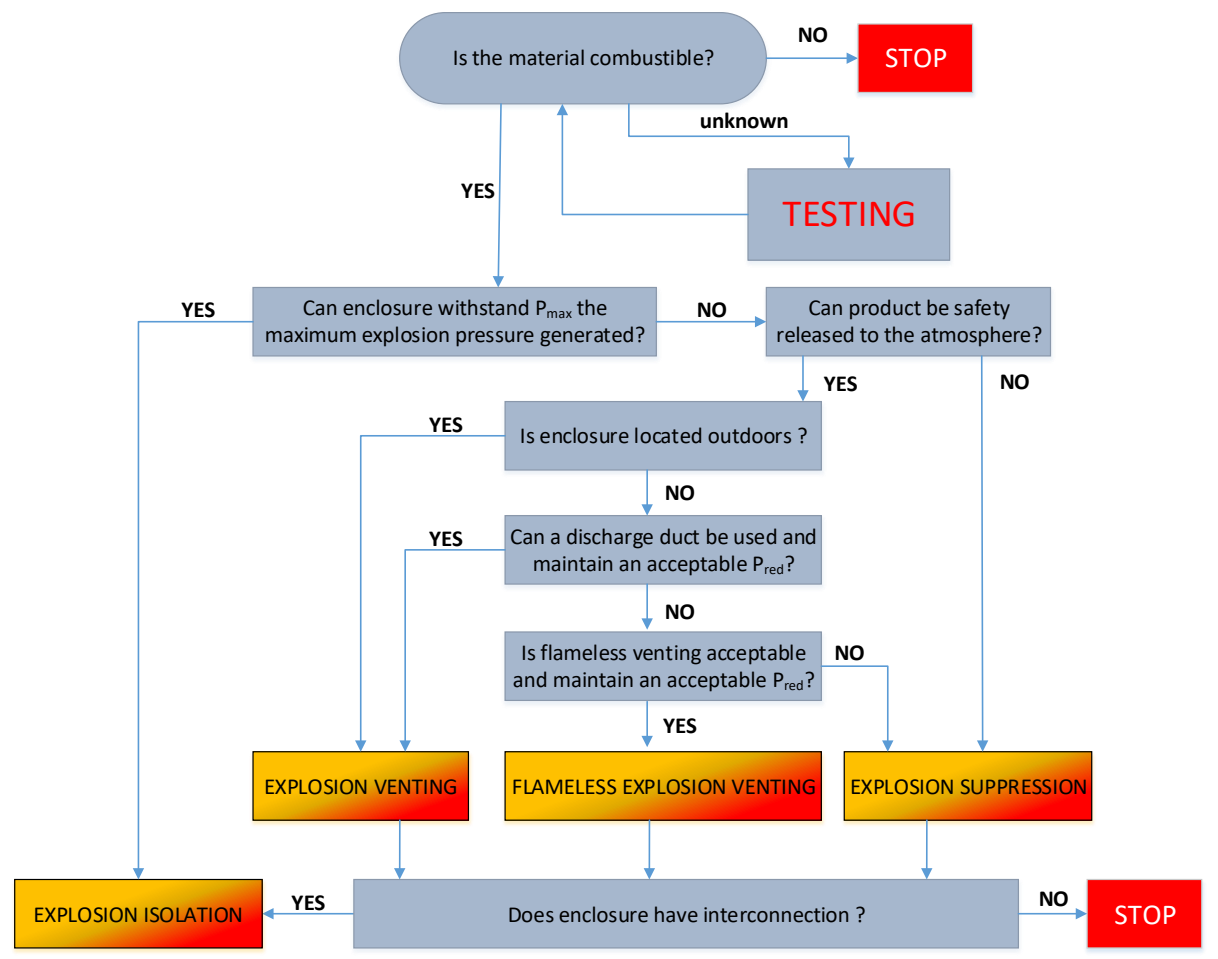

Fig. 5. Chart of explosion protection technique 


\section{Conclusions}

Explosion characteristics determination has a significant role in the first phase of the explosion risk assessment procedure and also for the design and selection of the proper protective systems intended to be used in potentially explosive atmospheres generated by dusts.

The logical diagram developed and presented within the paper shows the methodology for selecting technical explosion protection solutions (protective systems) such as explosion isolation, explosion venting, flameless explosion venting, explosion suppression, these depending on the technological processes encountered in practice. The logical diagram is a useful tool for safety engineers and practitioners who deal with the selection and application of protective systems in technological installations which circulate combustible dusts.

\section{References}

1. Directive 2014/34/EU of the European Parliament and of the Council of 26 February 2014 on the harmonization of the laws of the Member States relating to equipment and protective systems intended for use in potentially explosive atmospheres (2014)

2. SR EN 14034-1+A1: 2011, Determination of explosion characteristics of dust clouds - Part 1: Determination of the maximum explosion pressure pmax of dust clouds (2011)

3. SR EN 14034-2+A1: 2011, Determination of explosion characteristics of dust clouds - Part 2: Determination of the maximum rate of explosion pressure rise (dp/dt)max of dust clouds (2011)

4. SR EN 14460: 2018, Explosion resistant equipment (2018)

5. SR EN 14797: 2007, Explosion venting devices (2007)

6. SR EN 15089: 2009, Explosion isolation systems (2009)

7. SR EN 14373: 2006, Explosion suppession systems (2006)

8. A. Jurca, E. Ghicioi, M. Părăian, S. Burian, M. Darie, S. Sicoi, F. Păun, Implementation and carrying out of laboratory test stands required for conformity assessment of equipment intended for use in potentially explosive atmospheres generated by combustible dusts - IRECEEX, (Romanian) contract 43/2005 (INSEMEX Petroşani, 2005) 